Names of number among Malayan and Polyncsian tribes may he referred to as a proof of degeneracy. The sound "man" is 10,000 among the natives of Samoa and Tonga, as it is in Chinese, but it is 4,000 in the Sardwich islands, and 1,000 in New Zealand. Islanders avoid high numbers, and allow the significance of a name of high numbers to sink. This is proof of degradation. The reason why the arithmetical faculty among the New Zealanders has become weaker than elsewhere is because of their enormous distance from the continent of Asia. Samoa and Tonga are much mearer, and accorcingly in those islands the religious traditions, e.g. circumcision, resemble those of Asia very closely. The Polynesians formerly had a decimal arithmetic, now it has sunk in Australia to quaternary or quinary arithmetic. In Ponape, one of the Caruline group, and comparatively near to the continent, apiki is roo of men, trees, or yams, but I, O00 of eggs, cocoanuts, or stonss. In Chinese $p a k$ is 100. After centuries of use high numbers fuctuate in value, because the intellect of islanders declines in power as the effect of long-continued isolation. The ideas, names, and usages of civilisation are gradually lost, and with ihem the human intellect becomes dwarfed.

Frof. F. Muiller, after showing that the Polynesiaus could originally count to IoO, adds, "Dies ist gewiss ein Zeugniss fiur clie nicht greringe geistige Begalbung und frihzeitige Entwicklung dieser Volker." "The Polynesians, then, have sunk in power, and were, when visited by Capt. Cook, in a state of progressive clepradation.

The question raised by Mr. Tylor was only-"Did Dr. Mar. tius change his opinion about the degeneracy of Brazilian tribes?" 1)r. Peschel thinks he did, but has not yet given sufficient proof. While I venture to think that the question - "Is savage man a riegererated being?" can be solved in the affirmative by the careful comparison of facts, without our needing to know that cach scientific traveller holds this view, it would be most interesting to be assured that all such men are agreed upon it.

JOSEPH EDKINS

\section{Disuse as a Reducing Cause in Species}

Ix a letter of mine (NATURE, vol. ix. p. 36r), entitled "Natural Selection and Dysteleology," there occurs a footnote upon the ahove s!bject. As this footnote was rather carelessly written, I wish to explain my meaning more clearly.

In the first place, it is evident that the fact of disuse causing atroplyy in individuals is no proof that it likewise causes atrophy in spectes; for if it does so, the laws under which it operates in the two cases must be quite different-the one set Leing as exclusively related to Inheritance, as the other set are indejendent of this principle. The primary question therefore is: Woes inheritance here reproduce the character of immediate ancesturs, as in congenital atrophy, \&c. ; or of distant ancestors, 2s in mutilations, \&c.? I think there can be no reasorable unestion that it does the former, and so have no doubt that cistse is a cause of atrophy in species. The question as to d.

One sentence in the footnote I am explaining may be taken to inuly that the effects of disuse are exhausted in a few generations. Nohning can be further from my meaning. If disuse acts at all in species, its 1nodus opercurdz, as just stated, must be that of cansin variations which are capable of being inherited; conseguently, if disuse acts thus at all, it is impossible to assign limits tis its operation in time. The question, however, is, In what proportion are the effects of disuse in the parents reproduced in the offspring? Variations caused by disuse certainly differ from congenital variations, in that they are not fully inherited; and it is the degree in which they are inherited that must determine the rate at which disuse here operates. This degree, however, is minnown : we only know that it is something very small. Now as disuse is in competition with other reducing causes, the rapidity of its action is an important factor in the estimation of its probable effects.

By the omission of the word "proportional" near the end of the footrote, I appear to institute an absolute comparison betiven the effects of disuse in wild and in tame species. This, of course, would be abourd. What I mean is, that supposing dinuse to be the chief cause of atrophy in wild species, it lias not jorducrd so much effect in tame species as we should antecedentiy expect; for, although the facts are very scanty, so far as they go they tend to prove, that when ar organ is disused for several generations only, the rate of its reduction is much greater than it ought to be, supposing disuse to be the main * "Reise der Novara." Linguistichex Theil, I867, p. 287 cause of atrophy in our domestic animals, and supposing the action of this cause to be uniform.

It will be asked, If we thus in part reject this cause, what other have we to substitute? This, of course, is a collateral issue; but as it is an important one, it may here be discussed. I would suggest the cessation of selection (see NATURE, vol. ix. p. 440) as a co-operating cause, for it seems to me that this must have acted here to some extent, and if no other causes have been at work, this extent must be the complement of the effects due to disuse. For the sake of definition, therefore, we shall assume disuse to be in abeyance. Now, on this assumption, we should expect to find that atrophy proceeds more rapidly during the initial stages of reduction than subsequently. But without dwelling upon this point, what may we infer from the existing degree of atrophy in the affected organs of our domestic animals? Supposing the cessation of selection to be the only cause at work, what degree of atrophy should we here expect to find? Before I turned to the valuable measurements given in the "Variation," I concluded (Cf. NATURE, vol, ix. p. 44I) that from 20 to 25 per cent. is the maximum of reduction we should expect this unassisted principle to accomplish, in the case of natural as distingnished from artificially-bree organs. Now on calculating the average afforded by each of Mr. Darwin's tables, and then reducing the averages to parts of 100 , I find that the highest average decrease is 16 per cent., and the lowest 5 ; the averoge of the averages being rather less than I2. Only four individual cases fall below 25 per cent, , and of these two should be omitted (Cf. "Variations," p. 272). Thus, out of eighty-three examples, only two fall below the lowest average expected. Moreover, we should scarcely expect disuse alone to affect in so similar a degree such widely different tissues as are brain and muscle. The deformity of the stermum in fowls also points to the cessation of selection rather than to disuse. Further, the fact that several of our domestic animals have not varied at all is inexplicable upon the one supposition, while it affords no difficulty to the other. We have seen that disuse can only act by causing variations; and so we can see no reason why, if it acts upon a duck, it should not also act upon a goose. But the cessation of selection depends upon variations being supplied to it; and so, if from any reason a specific type does not vary, this principle cannot act. Why one type should vary, and another not, is a distinct question, the difficulty of which is embodied by the one supposition, and excluded by the other. For', to say that disuse has not acted upo type $A$, because of its inflexible constitution, while it has acted on a closely allied type $B$, because of its flexible constitution, is merely to insinuate that disuse having proved itself inadequate to cause reduction in the one case, it may not have been the efficient cause of reduction in the other. But the counter-supposition altogether excludes the idea of a casual connection, and so rests upon the more ultimate fact of differentisl variability, as not requiring to be explained. Lastly, it is remarkable that those animals which have not suffered reduction in any part of their bodies are likewise the animals which have not varied in any other way, and conversely; for as thexe is no observable connection between these two peculiarities, the fact of the intimate connection between them tends to show that special reduction depends upon general variability, rather than that special variability depends upon special reducing causes.

Dropping, however, our argmentative assumption, it will be remembered that I deem it in the last degree improbable that disuse should not have assisted in reducing the unused organs of our domestic animals; and the effect of this remark is to show that the cessation of selection is not able to accomplish so much reduction as I antecedently expected. On the other hand, it seems to me no less improbable that the cessation of selection should not have here operated to some extent; but in what degree the observable effects are to be attributed to this cause, and in what degree to disuse, I shall not pretend to suggest.

No doubt the above considerations are of a very vague de. scription; but this only follows from the scarcity of the data at cur disposal, and it is to this very scarcity that I am principally desirous of caling attention; for although it is with reluctant diffience that I venture thus, even in part, to dispute the doctrine of one whom most of living men I venerate, yet, for the reason just given, I carnot help feeling that the time has not yet arrived for a final quantitative decision upon this subject. However, as before remarked, "the question thus raised is of no practical importance; since whether or not disuse is the principal cause of atrophy in species, there is no doubt that atrophy $a c$ companies disuse."
GeORGE J. ROMANES 